ISSN: 2526-7884

Editor: Prof. Dr. Marconi Freitas da Costa

E-mail: cbr@ufpe.br
Avaliação: Double blind review

Recebido: 13 de Novembro, 2020

Aceito: 02 de janeiro, 2021

\title{
O VALOR SIMBÓLICO DA MARCA IPHONE PARA A BASE DA PIRÂMIDE
}

The symbolic value of the iPhone brand for the base of the pyramid

\author{
Alyce Cardoso Campos ${ }^{1}$ \\ ORCID: http://orcid.org/0000-0001-6903-9542 \\ E-mail: alycecardosoc@yahoo.com.br \\ Daniel Carvalho de Rezende ${ }^{1}$ \\ ORCID: http://orcid.org/0000-0003-1277-724X \\ E-mail: rezendedc@gmail.com
}

${ }^{1}$ Universidade Federal de Lavras, Lavras, Minas Gerais, Brasil

\begin{abstract}
Resumo
O conhecimento limitado sobre o consumo na base da pirâmide acaba impedindo que seja percebida a grande ênfase que esse segmento de consumidores coloca na cultura material. De modo a colaborar com estudos na temática, esta pesquisa teve como objetivo identificar os diferentes atributos ligados ao simbolismo da marca iPhone em comparação às diferentes marcas de smartphones, na visão dos indivíduos da base da pirâmide. Para isso, foram realizadas 24 entrevistas com indivíduos de baixa renda que possuem iPhone, utilizando a técnica Bola de Neve. 0 iPhone e a Apple são definidos como marcas fortes que ocupam um patamar diferenciado na percepção das pessoas, com o iPhone sendo apontado como um celular de luxo. Os participantes afirmam que outros smartphones são vistos com inferioridade e muitas vezes os
\end{abstract}

\begin{abstract}
The limited knowledge about consumption at the base of the pyramid ends up preventing the great emphasis that this segment of consumers places on material culture from being perceived. In order to collaborate with studies on the theme, this research aimed to identify the different attributes linked to the symbolism of the iPhone brand compared to the different smartphone brands, in the view of individuals at the base of the pyramid. For this, 24 interviews were carried out with lowincome individuals who own an iPhone, using the Snowball technique. The iPhone and Apple are defined as strong brands that occupy a different level in people's perception, with the iPhone being considered as a luxury cell phone. Participants claim that other smartphones are viewed with inferiority and often iPhone users call their
\end{abstract}


usuários de iPhone chamam seus aparelhos de "meu iPhone" e não de "meu celular". Apontam ainda que a maioria das pessoas vê grande status no smartphone da Apple e afirmam que, por mais que muitas vezes não assumam, é visível a compra por status. Existe uma ligação entre iPhone e riqueza, sendo o prestígio oferecido pelo aparelho algo que agrada os indivíduos de baixa renda.

Palavras-chave: Apple; Simbolismo de marca; Baixa renda; Consumo. devices "my iPhone" and not "my cell phone". They also point out that most people see great status on the Apple smartphone and claim that, as much as they often do not assume, the purchase by status is visible. There is a link between iPhone and wealth, and the prestige offered by the device is something that appeals to low-income individuals.

Keywords: Apple; Brand symbolism; Low income; Consumption.

This work is licensed under a Creative Commons Attribution 4.0 International License.

\section{INTRODUÇÃO}

Em 1998, Prahalad e colegas introduziram o termo base da pirâmide (Kolk, Rivera-Santos, \& Rufín, 2014). Prahalad, referência no assunto, aponta que a Base da Pirâmide (BdP) é composta por pessoas com baixo poder aquisitivo, somando mais de 4 bilhões de pessoas no mundo, que vivem com até 2 dólares por dia (Prahalad, 2005). Porém, é relevante destacar que a definição de baixa renda não resulta somente de quantos dólares o indivíduo recebe por dia, mas também do estilo de vida que levam. Com isso, outros autores estabeleceram formas distintas de definir quem faz parte da BdP, como por exemplo, Yurdakul, Atik e Dholakia (2017) que afirmam que qualquer indivíduo que se sinta angustiado por não possuir uma vida minimamente decente, se sentindo excluído socialmente mesmo sem estar em situação de fome, pode ser considerado pertencente à base da pirâmide. Não apelando para o fato de que os desejos dos seres humanos são infinitos, mas tratando de os indivíduos sentirem ter uma vida decente.

Barros (2006) afirma que é tão limitado o conhecimento sobre o consumo na base da pirâmide que acaba impedindo que seja percebida a grande ênfase que esse segmento de consumidores de baixa renda coloca na cultura material. É por meio da posse que se distinguem de outros mais pobres e acreditam que estão em direção ao "mundo dos ricos". Na pesquisa realizada por Castilhos (2007), os entrevistados falam sobre "saber gastar". Muitas vezes disseram que o problema do pobre é não saber gastar o dinheiro. Saber gastar seria investir em bens mais valorizados, que lhes dão algum tipo de distinção. Marcas ambiciosas são importantes para os consumidores da base da pirâmide. 0 consumo se mostra mais eficiente ainda quando é usado como diferenciação intra-classes, pois existe uma distinção entre os pobres e os "pobres-pobres" e essa diferenciação se estabelece prioritariamente pela posse de bens (Castilhos, 2007).

No momento em que um cidadão de baixa renda compra um produto de marca, sente que se aproxima de pessoas da classe mais elevada, saindo da invisibilidade e ganhando autoestima. É uma forma de se diferenciar de indivíduos extremamente pobres, que não podem pagar por esses produtos (Barki \& Parente, 2010). Com o consumo sendo algo central na vida social, pode-se dizer que muitas vezes o valor social das pessoas é apontado pelo que elas possuem e não pelo que elas são (Barbosa, 2004).

Os smartphones são objetos que passaram a ter grande utilidade e importância no dia a dia das pessoas. Segundo a EAESP-FGV (2018), existe mais de um aparelho por pessoa no Brasil. Autores como Barros e Rocha (2007), Castilhos (2007) e Yurdakul, Atik e Dholakia (2017) apontam em seus estudos que eletroeletrônicos são fortes produtos que inserem pessoas com baixo poder aquisitivo na sociedade de consumo e que celulares e produtos de marca de destaque colaboram com a luta contra o medo da exclusão e humilhação. 0 iPhone, smartphone da Apple, foi escolhido para a pesquisa devido a ser um bem de marca forte e mundialmente conhecido, facilitando assim o entendimento e o interesse de pesquisadores de diversos países neste estudo. Em suas observações diárias, os autores deste artigo perceberam a valorização que indivíduos da base da pirâmide dão ao iPhone, despertando o interesse em estudar sobre o tema. Além disso, apesar da base da pirâmide ter ganhado destaque nos 
últimos anos, são poucos os estudos no assunto, principalmente sobre consumo de luxo. Entender o comportamento de compra desse segmento numeroso é importante para conhecer um significativo setor da economia brasileira (Natt et al., 2017). Assim, de modo a buscar ampliar o conhecimento sobre a população de baixa renda, o objetivo deste artigo foi identificar os diferentes atributos ligados ao simbolismo da marca iPhone em comparação às diferentes marcas de smartphones, na visão dos indivíduos da base da pirâmide.

\section{REFERENCIAL TEÓRICO \\ Consumo simbólico}

Uma marca compreende aspectos funcionais e simbólicos. Os quesitos funcionais são os que satisfazem necessidades práticas e imediatas, como por exemplo, um relógio que tem como utilidade a capacidade de informar a hora certa. Os aspectos simbólicos, por sua vez, são os que satisfazem necessidades que tratam do prestígio e da autoexpressão, e são usados principalmente para o apelo de status (Bhat \& Reddy, 1998; Esmaeilpour, 2015). É possível que as marcas apresentem tanto significados funcionais quanto simbólicos para os consumidores. Além disso, Elliott e Wattanasuwan (1998) declaram que todo consumo voluntário demanda, consciente ou inconscientemente, valores simbólicos. Se o indivíduo tiver escolha, ele optará por consumir os bens que possuem significados simbólicos. Corroborando, Kim e Jang (2017) descobriram, através de suas pesquisas, que os atributos simbólicos são mais determinantes nas intenções de compra do que os funcionais. 0 valor econômico dos bens, ou seja, o alto valor monetário cobrado por eles é um ponto que ajuda a atribuir-lhes valor simbólico (Mccracken, 2003).

A existência do consumo conspícuo, hedônico e de identidade tem forte influência na construção de relações sociais, em vez de simplesmente satisfazer necessidades básicas. Os bens podem ser fontes de representação que buscam atender necessidades sociais de identificação a um grupo. Isso é conhecido como consumo simbólico, um olhar além dos aspectos funcionais que podem levar ao consumo (Chaves \& Rodriguez-González, 2013), considerando o significado cultural de produtos ou serviços (Bezerra \& Davel, 2017).

A cultura material tem a habilidade de carregar mensagens de status devido às propriedades simbólicas que estão presentes nos objetos. Todos os bens materiais têm seu caráter simbólico e podem se tornar um meio para expressão e também de transformação (Mccracken, 2003). 0 indivíduo se esforça continuamente para construir e também manter sua identidade. Para atingir esse objetivo, utiliza os significados simbólicos dos objetos, sendo uma oportunidade para as marcas exercerem uma função importante no projeto simbólico do self (Elliott \& Wattanasuwan, 1998). O simbolismo de marca é um conceito que inclui o prestígio e a expressão da personalidade (Bhat \& Reddy, 1998).

Tangsupwattana e Liu (2018) realizaram um estudo em que os resultados apontam que o consumidor cria um vínculo com produtos ou serviços que possam impulsionar seu status. A utilização de bens simbólicos, considerados de excelência, constitui um dos indicadores privilegiados da "classe", sendo um instrumento de estratégias de distinção (Bourdieu, 2008). Segundo Goffman (1951), um importante símbolo de associação a uma determinada classe é exposto em uma interação informal. Conforme os tipos de atitudes, tal pessoa é vista pelos outros como "um dos nossos".

Bourdieu (2008) coloca que os gostos funcionam como indicadores privilegiados da "classe" e que nada distingue mais a classe do que a capacidade de aquisição de bens. Também traz a ideia de que os indivíduos se diferenciam pelas distinções que eles realizam entre o que é belo e o que é feio, distinto e vulgar. Bourdieu buscou relatar que, na época, havia uma divisão entre uma alta cultura, da elite, e uma cultura popular. Além disso, quanto à posse de bens, a competência cultural e a disposição culta que são apreendidas através das posses variam de acordo com as categorias de quem os opera e também do ambiente em que eles se aplicam (Bourdieu, 2008). De acordo com Senna e Hemai (2017), em se tratando de uma mesma classe, a distinção social entre consumidores não ocorre apenas pela quantidade de bens que adquirem, mas também por quais produtos têm entre suas posses. A decisão sobre o que consumir tem grande influência do capital cultural que é obtido por cada indivíduo. Enquanto sujeitos de baixo capital cultural apreciam a compra e a posse, os de alto capital cultural 
tendem a dar maior importância aos momentos e experiências que o consumo está propiciando (Senna \& Hemai, 2017).

Em uma pesquisa realizada sobre o consumo de acessórios femininos por mulheres de baixa renda com o objetivo de adquirir maior compreensão acerca do universo do consumo simbólico, Natt et al. (2017) observaram a existência de experiências de consumo que ocorrem com a finalidade de marcação de presença no universo social. A partir do consumo, as mulheres se apoderam dos significados e símbolos que compõem os bens, como pertencimento a um grupo, autoconfiança e poder, sendo capazes de resgatar sua autoestima e de se relacionar com pessoas ao seu redor. Os autores afirmam que a aquisição de determinados bens está relacionada ao status social que eles representam e aos seus significados para certos grupos sociais.

\section{Marcas Apple e iPhone}

Um gasto de milhões de dólares a cada ano é direcionado à criação e suporte de imagens da marca. Posicionar uma marca com uma imagem clara e consistente é um dos principais desafios das empresas (Bhat \& Reddy, 1998). O smartphone da Apple, o iPhone, é um exemplo de sucesso, conseguindo alcançar grande prestígio no mercado. Quando o iPhone foi anunciado em 2007, foram mais de 500 mil unidades vendidas no primeiro fim de semana, além de dias de filas de consumidores em busca do aparelho (Laugesen \& Yuan, 2010).

A Apple provocou uma revolução no setor de telecomunicações através de uma série de produtos que obtiveram grande sucesso, fazendo uso de uma estratégia rara de diferenciação, admiravelmente difícil de ser imitada. Ela foi premiada durante sete anos seguidos (2005-2011) como a empresa mais inovadora do mundo pela Business Week e também liderou as empresas mais admiradas do mundo por cinco vezes (2008-2012). A sua diferenciação permite que continue cobrando preços mais altos e, com isso, tenha capital para financiar outras inovações (Heracleous, 2013). Perante a todo esse sucesso, a Apple foi a primeira empresa de capital aberto no mundo a valer 1 trilhão de dólares (BBC, 2018).

De acordo com o jornal Folha de São Paulo (2018), ter um iPhone em 2016 nos Estados Unidos era sinal de riqueza e era o melhor indicativo de que um indivíduo pertencia ao grupo dos mais ricos do país. Além disso, a matéria apresenta que nenhuma marca individual foi tão indicativa de pertencimento à alta renda do que ter um iPhone. A relação entre iPhone e indivíduos de alta renda não é recente. Desde 2007, ano em que o produto foi lançado, o preço dos aparelhos tem selecionado seu público.

A Apple ostenta certo prestígio em razão de sua tecnologia e qualidade nos produtos serem diferenciadas (Jacomino, Biggi, \& Pépece, 2018). Como resultado da pesquisa, as autoras acima citadas encontraram que o status é proporcionado pela posse do iPhone diante do grupo social e também da sociedade como um todo. Os entrevistados demonstraram possuir forte apego e fidelidade à marca iPhone e confirmaram que ele é altamente reconhecido, mesmo por pessoas que não sejam usuárias do produto, manifestando assim a diferenciação da marca. Também declararam o poder do iPhone de oferecer status, prestígio e superioridade tanto em relação aos outros aparelhos quanto do indivíduo perante os grupos nos quais ele se insere. Além disso, houve até quem afirmasse ser melhor atendido em lojas por possuir um iPhone. Outro ponto revelado é que a maioria dos participantes da pesquisa adquiriram o iPhone por influência de outras pessoas, principalmente familiares e amigos, reforçando a ideia de compra como um meio de integração ao seu grupo social.

O smartphone se tornou um objeto de desejo e que faz parte do dia-a-dia da maioria dos indivíduos. Devido ao avanço tecnológico nos últimos anos, esse objeto tem demonstrado grandes avanços e uma aceitação cada vez maior por parte do consumidor (Baumhammer, Silva, \& da Costa, 2017). Um estudo realizado por Martins, Oliveira e Corso (2018) apontou que o smartphone pode ser visto como uma extensão da identidade de seu usuário devido ao grau de envolvimento entre eles, possuindo muitas vezes um forte apego emocional com o aparelho.

Özbölük e Dursun (2017) realizaram um estudo netnográfico em uma comunidade de marca on-line dedicada à Apple e traçaram cinco perfis diferentes de acordo com seus interesses e compromissos com a marca: o aprendiz, que está num processo de aprendizagem da marca; o 
pragmático, que considera de grande importância o processo de decisão de compra, não adquirindo antes de muita pesquisa e que, além disso, compartilham suas experiências de consumo com outras pessoas; o ativista, que são disseminadores de informações, especialistas no uso da marca, seguem os últimos lançamentos e compartilham satisfações e insatisfações; o líder de opinião, que são usuários com um interesse mais profundo, se veem como donos da marca, acreditam que a lealdade que demonstram os distingue dos outros e que, por possuírem um senso de propriedade da marca, não aceitam falhas e costumam ter atitudes críticas; e por último, o evangelista, que são membros que desenvolvem um profundo vínculo emocional, apreciam todas as conquistas da marca, inspiram outras pessoas e são defensores da marca em todas as circunstâncias. Atingir este último perfil é algo extremamente complexo e a Apple conseguiu alcançá-lo. Mesmo com a forte concorrência de outras marcas que apresentam inovações atraentes e até melhores, o simbolismo proporcionado pela compra de um aparelho Apple motiva a escolha desta marca.

\section{METODOLOGIA}

Este estudo teve como objetivo identificar os diferentes atributos ligados ao simbolismo da marca iPhone em comparação às diferentes marcas de smartphones, na visão dos indivíduos da base da pirâmide. Para isso, optou-se pelo método qualitativo por ser interessante para o entendimento não só no processo de formação de opinião própria e decisão individual, mas também do indivíduo em seus grupos sociais estando sujeito a receber e transferir variadas influências. Foram realizadas entrevistas em profundidade por permitirem alcançar pontos que muitas vezes não conseguem ser obtidos por meio de questionário estruturado. Em uma entrevista, para explorar verdadeiramente o assunto, o entrevistador tem a liberdade de conduzir a situação como considerar ser adequada, absorvendo a história e experiências de vida do entrevistado, como ele se comporta diante de certas situações, como reage às opiniões alheias (Veiga \& Gondim, 2001).

No total, foram realizadas 24 entrevistas com pessoas de baixa renda que possuem iPhone, realizadas entre junho e dezembro de 2019 , sendo dezenove executadas pessoalmente nas cidades de Lavras e Governador Valadares, duas por meio de vídeochamada e três por ligação telefônica. Todas as entrevistas foram realizadas em um único encontro com cada participante, com uma média de 40 minutos cada. Além das duas cidades citadas, esse estudo também contou com entrevistados das cidades de São Paulo (SP), Petrópolis (RJ), Juiz de Fora (MG), Uberaba (MG), Caratinga (MG) e Conselheiro Pena (MG). Os dados demográficos dos entrevistados são apresentados no Quadro 1.

\begin{tabular}{|c|c|c|c|}
\hline Entrevistado no & Sexo & Idade & Ocupação \\
\hline Entrevistado 1 & Masculino & 31 anos & Estudante universitário \\
\hline Entrevistado 2 & Masculino & 27 anos & Estudante universitário \\
\hline Entrevistado 3 & Masculino & 18 anos & Estudante universitário \\
\hline Entrevistado 4 & Masculino & 22 anos & Estudante universitário \\
\hline Entrevistado 5 & Masculino & 23 anos & Estudante universitário \\
\hline Entrevistado 6 & Feminino & 23 anos & Estudante universitário \\
\hline Entrevistado 7 & Feminino & 23 anos & Estudante universitário \\
\hline Entrevistado 8 & Masculino & 22 anos & Estudante universitário e vendedor de ingressos de \\
\hline Entrevistado 9 & Feminino & 22 anos & Estudante universitário \\
\hline Entrevistado 10 & Masculino & 21 anos & Estudante universitário e motoboy \\
\hline Entrevistado 11 & Feminino & 19 anos & $\begin{array}{c}\text { Estudante universitário e vendedora de ingressos de } \\
\text { festas }\end{array}$ \\
\hline Entrevistado 12 & Feminino & 20 anos & Estudante universitário \\
\hline Entrevistado 13 & Feminino & 18 anos & Estudante universitária e maquiadora \\
\hline
\end{tabular}




\begin{tabular}{|l|l|l|l|}
\hline Entrevistado 14 & Masculino & 22 anos & Estudante universitário \\
\hline Entrevistado 15 & Masculino & 23 anos & Estudante universitário \\
\hline Entrevistado 16 & Feminino & 20 anos & Estudante universitário \\
\hline Entrevistado 17 & Feminino & 21 anos & Estudante universitário \\
\hline Entrevistado 18 & Feminino & 18 anos & Estudante universitário \\
\hline Entrevistado 19 & Masculino & 24 anos & Estudante universitário \\
\hline Entrevistado 20 & Feminino & 24 anos & Empresária de pequeno porte \\
\hline Entrevistado 21 & Feminino & 53 anos & Autônoma \\
\hline Entrevistado 22 & Feminino & 24 anos & Estudante universitário \\
\hline Entrevistado 23 & Masculino & 19 anos & Estudante universitário \\
\hline Entrevistado 24 & Masculino & 20 anos & \\
\hline
\end{tabular}

Fonte: Elaborado pela autora.

Quadro 1. Dados demográficos dos entrevistados

Devido à falta de uma classificação padrão que defina a renda de cada classe social, os autores optaram por utilizar o critério de vulnerabilidade utilizado pela Universidade Federal de Lavras (UFLA) e pela Universidade Federal de Juiz de Fora - Campus Governador Valadares (UFJF-GV). A escolha se deu devido aos entrevistadores possuírem maior facilidade de contato com os estudantes de baixa renda. Ambas as universidades analisam dados socioeconômicos do estudante e sua família, como bens, imóveis, veículos, condições de moradia, se o aluno estudou em escola pública ou privada (com bolsa ou sem), dentre outros. Toda a documentação comprobatória deve ser entregue para a PróReitoria de Assuntos Estudantis e Comunitários (UFLA) e para a Pró-Reitoria de Assistência Estudantil (UFJF-GV).

A técnica de amostragem Bola de Neve (Snowball) foi utilizada, solicitando aos alunos destas universidades que indicassem novos participantes com o perfil necessário para a pesquisa (Vinuto, 2014). Algumas vantagens da Bola de Neve como forma de seleção são que os entrevistados têm maior facilidade em conhecer outro indivíduo que se encaixe nos mesmos quesitos escolhidos para a pesquisa (Albuquerque, 2009) e que essa técnica pode trazer respondentes de diversas localidades com as indicações dos entrevistados. 0 corpus de pesquisa não se limitou a estudantes universitários, pois poderiam indicar outras pessoas que tivessem o mesmo padrão social. Para não invadir a privacidade dos entrevistados, não foi questionado diretamente sobre a renda familiar mensal. A confirmação de que os participantes faziam parte do público alvo da pesquisa se deu através de um bate papo em que os pesquisadores sondaram as condições do indivíduo. Somente duas indicações não se enquadraram no perfil do estudo e não puderam participar das entrevistas.

As entrevistas foram transcritas mantendo a forma original da expressão dos entrevistados e para a análise dos dados, foi utilizada a técnica de análise de conteúdo de Bardin (1977). As categorias foram pré-estabelecidas de acordo com o objetivo da pesquisa e o referencial teórico utilizado, sendo estas (i) valor da marca iPhone e (ii) iPhone perante aparelhos de outras marcas.

\section{RESULTADOS E DISCUSSÃO}

De modo a identificar os diferentes atributos ligados ao simbolismo da marca iPhone em comparação às diferentes marcas de smartphones, na visão dos indivíduos da base da pirâmide, duas sessões foram criadas nos resultados com o intuito de discutir separadamente o valor da marca iPhone para a baixa renda e as comparações realizadas por eles entre o iPhone e os smartphones de outras marcas.

\section{Valor da marca iPhone}

O status é muito citado quando questionados sobre o que as marcas Apple e iPhone representam. $\mathrm{O}$ aparelho é citado como um celular de luxo. Além disso, enxergam as marcas como 
referência de qualidade, praticidade, rapidez, que lançam as tendências e que dominam o setor, ostentando certo prestígio em razão de sua tecnologia e qualidade diferenciada, como é apontado por Jacomino, Biggi e Pépece (2018). Mesmo com a questão do ego presente no momento das entrevistas, muitos aspectos simbólicos (Bhat \& Reddy, 1998; Chaves \& Rodriguez-González, 2013; Esmaeilpour, 2015) foram ditos pelos entrevistados.

\footnotetext{
"Nossa, esse celular é o bonito, é o chique, é o rico" (Entrevistado 10).

"As pessoas nem falam 'ah, meu telefone', falam 'meu iPhone'” (Entrevistada 7).

"É um celular que todo mundo quer ter, né? É um celular famoso. Todo mundo quer ter. [...] A marca, né, da maçãzinha, como todo mundo fala" (Entrevistada 12).

"Ah, status, porque nem todo mundo tem iPhone. [...] Se você tem um iPhone X, XR agora, você é rei. É isso" (Entrevistado 5).
}

Uma grande diferenciação pode ser vista em relação à marca na fala dos entrevistados 7 e 10 , que apontam que as pessoas se referem ao seu smartphone como "meu iPhone" e o percebem como o celular "chique", o "rico". Ter um iPhone já é sinônimo de status, porém na visão do entrevistado 5, quem tem as versões mais novas dispõe de muito mais prestígio, podendo ser considerado "um rei". Isso vai de acordo com a matéria do jornal Folha de São Paulo (2018), que divulgou que ter um iPhone em 2016 nos Estados Unidos era sinal de riqueza, o melhor indicativo de que a pessoa pertencia ao grupo dos mais ricos do país. Outra curiosidade é a visão de que ele é tão bom, que alguns têm o pensamento de que todas as pessoas têm o desejo de possuir um iPhone. Também foi mencionada a questão do consumismo, do desejo de sempre adquirir outro mais recente, citando que a marca trabalha intensamente para despertar o interesse:

"Consumismo. Muito porque igual eu falei, quando você tem um, aí você compra, passa 3 meses lança outro. Você fica louco 'meu Deus do céu, eu quero o outro'. Eu 'tô' louca igual com o iPhone $\mathrm{X}$ agora. Eu 'tô' com esse aqui eu não sei nem como ainda. Por falta de dinheiro mesmo" (Entrevistada 18).

A entrevistada de número 18 e diversos outros afirmam que ainda não trocaram seus iPhones por outros mais recentes por falta de condições financeiras. Alguns apontam que estão trabalhando muito e economizando com foco na futura compra. Com isso, podem ser vistos tanto o forte desejo de possuir versões mais novas, quanto os sacrifícios que estão dispostos a fazer para adquirir o aparelho. Afinal, como apresenta Jacomino, Biggi, \& Pépece (2018), o iPhone proporciona diversos benefícios simbólicos para o indivíduo, como status, prestígio, superioridade, valorização, tanto em relação aos outros aparelhos quanto do indivíduo perante os grupos nos quais ele se insere ou busca se inserir. Além da forte divulgação, outro ponto interessante que colabora com essa fidelização foi citado, a experiência que é proporcionada ao usuário.

"E toda experiência de você abrir. Eu 'tava' estudando um pouco mais o quadro e eles
pensam realmente em como isso vai ser entregue, o valor para o cliente. Então a caixa
dele, como ele vem, tipo, tudo, a questão de como você inicia ele. Todas as etapas. Ele
preza muito por essa fidelização, tipo assim, pela experiência do usuário"
(Entrevistada 6).

Dois pontos interessantes podem ser vistos nessa fala. A experiência que é proporcionada, ativando aspectos sentimentais no comprador e criando uma sensação de ligação com a marca, e o interesse do entrevistado em estudar sobre a importância que a Apple coloca nessa entrega de valor. Pode ser percebido então a tentativa da Apple de fazer com que o consumidor se sinta parte da marca, buscando fazer com que haja um vínculo emocional e se torne um perfil evangelista, como é apresentado por Özbölük e Dursun (2017). Eles trazem cinco perfis diferentes de acordo com o interesse e compromisso do usuário de iPhone: o aprendiz, o pragmático, o ativista, o líder de opinião e o evangelista, sendo este último os membros que desenvolvem um profundo vínculo emocional com 
a marca, defendendo-a e inspirando outras pessoas a se tornarem usuárias e fãs. Outros casos de sentimento de vínculo com a marca podem ser vistos nos trechos a seguir:

"Desde então, quando eu possuí o primeiro iPhone, eu tive todos os modelos até
chegar no que eu tenho hoje. Isso aí já faz uns 12 anos que eu faço uso do IOS. [...] eu
peguei ele desde o começo, então eu sei as melhorias, eu sei... acompanhei o
crescimento da empresa e tal" (Entrevistado 1).
"Eu babo muito ovo da Apple né. Para mim a Apple fez uma história com iPhone"
(Entrevistado 8).

Ainda de acordo com o estudo netnográfico de Özbölük e Dursun (2017), autores que traçaram os cinco perfis diferentes em relação à marca Apple, de acordo com as falas dos entrevistados acima, pode-se perceber traços dos dois perfis mais profundos e difíceis de alcançar: o perfil líder de opinião, por se definir como entendedor da marca, se distinguindo dos outros por conhecer as melhorias e ter acompanhado o crescimento da empresa, e o perfil evangelista, em que os consumidores desenvolvem um profundo vínculo emocional com a marca, apreciando e sendo defensor em todas as circunstâncias, como pode ser visto na expressão "baba-ovo", que significa puxa-saco, bajulador.

Outra questão que mostra o quanto as pessoas valorizam a marca iPhone é o alto número de roubos. Os roubos acontecem devido ao preço elevado do produto. Mesmo que não seja possível realizar a venda do smartphone após o roubo devido ao bloqueio por parte do dono, as peças são facilmente vendidas, tendo a opção de desmontar o aparelho, vendendo as peças separadamente. Muitos entrevistados dizem ter medo de serem roubados pelo fato do smartphone da Apple chamar muito a atenção. Um caso é contado pela entrevistada 6.

"A minha irmã tinha um celular que ele não era um iPhone, mas ele tinha a bolinha.
Parece, mas não chegava a ser uma imitação. Só era branco e de longe ele aparentava
ser um iPhone. E aí no transporte público tiraram da bolsa dela e roubaram. Não fazia
sentido ter roubado um celular daquele, entendeu? Porque ele era horrível, mas a
aparência dele lembrava um iPhone de longe. A pessoa, rápido, ela ia associar a um
iPhone e ia roubar" (Entrevistada 6).

Além de enxergar o iPhone de maneira diferente, os entrevistados afirmam que as pessoas distinguem os usuários desse smartphone, pois pensam que eles têm maior condição financeira e fazem comentários no sentido de que quem possui um iPhone é "riquinho", "burguês". Logo, é possível perceber o quanto o iPhone tem sua presença marcada no universo social, sendo um bem que representa status e que traz significados distintos para certos grupos sociais (Natt et al., 2017). Imaginam que se o indivíduo tem condições de comprar um iPhone, um smartphone caro, tem também de adquirir outros bens de preço elevado.

"Nossa, fulano tem condição né, 'tá' usando iPhone" (Entrevistada 16).

"Às vezes você vê uma pessoa que tem iPhone, às vezes você sente 'olha, essa pessoa tem isso aqui, isso aqui, isso aqui', entendeu? Atende isso aqui, essa qualidade, tem esse poder aquisitivo aqui, potencialmente ela deve ter outros tipos de coisas também que são um pouquinho mais elevados em questão de custo" (Entrevistado 4).

"Tem pessoas que acham que o iPhone vale mais que uma peça de roupa. A pessoa vai bater o olho em você e vai te achar diferente" (Entrevistada 17).

"É um aparelho bonito que chama muito a atenção. E eu acredito que as pessoas olhem 'ah, aquela pessoa é bem-sucedida" ou "aquela pessoa tem dinheiro"” (Entrevistada 20).

Alguns declaram que, quando não eram usuários, também enxergavam de maneira diferente quem possuía o aparelho (Jacomino, Biggi, \& Pépece, 2018). Mas a maioria, por mais que não admita claramente, faz diferenciação de quem tem e quem não tem um iPhone. Isso é percebido pelo receio de um dia terem que usar um aparelho Android novamente. Seria uma queda no patamar que ocupam. Os entrevistados apontam que quando ganharam ou compraram o smartphone da Apple, notaram a 
diferença na maneira como eram tratados. Com isso, houve uma sensação de estar em direção ao "mundo dos ricos" (Barros, 2006).

"Na época que eu ganhei, as pessoas 'hum, 'tá' de iPhone. Olha lá ele e tal"' (Entrevistado 8).

"Quando eu ganhei, eu ganhei no ano que lançou. Então o meu celular era novo e eu sou de escola pública. Então, tipo assim, quando eu ganhei, nossa, eu era a rica da sala. 'Nossa, mas você é muito rica, né?'” (Entrevistada 17).

"Você chega com iPhone, 'pô o cara tem um iPhone, velho"' (Entrevistado 10).

Essas frases apontam o valor social que é colocado nas pessoas devido ao que elas possuem e não pelo que elas são (Barbosa, 2004), dando grande valor aos bens materiais. Um caso interessante foi apresentado pela entrevistada número 18. Ela conta o receio que o atual namorado sentiu ao conhecê-la e perceber que ela possuía um iPhone, tendo o pensamento de que seria difícil despertar interesse em uma garota rica.

"Quando eu conheci meu namorado. Aí ele viu que eu tinha esse celular aqui, né? Aí ele ficou tipo 'meu Deus do céu, que que eu vou arrumar para conversar com essa menina? Ela é rica. Não sei falar'" (Entrevistada 18).

Alguns apontam que essa forma como são vistos muitas vezes não condiz com a realidade, pois muitas pessoas, como elas, não são de classe elevada e possuem o aparelho, seja por meio de sacrifícios ou por meio de formas alternativas de aquisição, como comprar um aparelho usado. Sendo assim, nem sempre é o que acontece, mas é como são percebidos, como pessoas com maior poder aquisitivo devido a possuírem um bem caro como o iPhone. 0 preço alto, inclusive, é um dos pontos que colabora para que seja atribuído ao aparelho um grande valor simbólico, como é colocado por McCracken (2003).

"Se eu tenho um iPhone, quer dizer que eu tenho poder aquisitivo. Nem sempre é isso, mas é isso que passa. Se eu chegar e fizer assim [mostrar o iPhone], você às vezes nem vai olhar para mim, mas você vai falar 'tem um iPhone!'” (Entrevistada 6).

"Olha, você tem um iPhone. Burguês!", entendeu? Então, na maioria das vezes, nem sempre vai ser assim. Isso vai ser relativo. [...] Igual 'tô' te falando, mil reais você compra um 6. Você tem um iPhone. [...] Mas no geral, pessoas que têm, geralmente têm uma condição boa sim" (Entrevistado 10).

O iPhone e a Apple ocupam um patamar diferenciado na percepção das pessoas. Com isso, pessoas de baixa renda acabam por conseguir se aproximar dessa visão privilegiada por possuir o aparelho. Muitos demonstram forte apego e também fidelidade à marca, se considerando conhecedores. Com isso, os dados obtidos vão de acordo com as pesquisas de Laugesen e Yuan (2010) e Heracleous (2013), que afirmam o sucesso do iPhone diante da rara estratégia de diferenciação da Apple, o que resultou em filas durante o lançamento e prêmios durante anos seguidos, permanecendo valorizado até os dias de hoje.

\section{IPhone perante aparelhos de outras marcas}

Os entrevistados apontaram diversos aspectos funcionais que diferem o iPhone de outros smartphones de outras marcas. O que mais valorizam é a facilidade de uso do sistema IOS e o fato do aparelho não travar, sendo mais rápido que os outros. Também citam que se sentem mais seguros por não haver possibilidade de ser contaminado por vírus e por possuir as opções de busca do iPhone e de bloqueio dos dados em caso de perda do smartphone, tendo segurança tanto das informações quanto do aparelho. 
"É tudo muito rápido. O Android, na maioria dos casos [...] passam um ano, o telefone já começa a travar, telefone já não funciona alguma coisa. É lento, entendeu?" (Entrevistado 1).

Quando questionados sobre as diferenças que veem quando o iPhone é comparado aos outros smartphones de outras marcas, a câmera é citada pela maioria dos entrevistados, tendo uma valorização muito evidente. A maioria dos respondentes trazem exemplos de amigos e conhecidos que sempre pedem para tirar fotos nos seus aparelhos devido à qualidade da fotografia. Alguns apontam fortemente a rejeição pela câmera de outras marcas e afirmam que para obter uma câmera em um aparelho Android com a mesma qualidade do iPhone, só seria possível pagando preços muito mais altos.

\footnotetext{
“Toda vez que vai usar para tirar foto ou alguma coisa, 'ah, pega o iPhone que é melhor"' (Entrevistado 2).

"Ele é mais rápido que o Samsung, trava menos e estética dele também é bem mais bonita, a câmera, Nossa Senhora, não me mostra uma câmera de Samsung não que eu morro" (Entrevistada 13).

"Um aparelho deles [iPhone] com preço mais inferior tem uma câmera de qualidade, mas para você ter a mesma qualidade em outro aparelho é tipo com preço bem mais caro assim" (Entrevistada 17).
}

Existe uma divisão quanto a questão de duração do aparelho. Enquanto uns afirmam que o IPhone dura muitos anos sem travar, outros trazem a questão da obsolescência programada, em que a Apple propositalmente desenvolve os modelos do aparelho de modo que se tornem obsoletos em determinado período de tempo, forçando o consumidor a comprar uma nova versão do smartphone. Porém, mesmo acreditando nisso, continuam preferindo utilizar o iPhone. Alguns exemplos podem ser vistos a seguir.

\begin{abstract}
"Por exemplo, eu tenho um iPhone que ele deve sido lançado em 2015 mais ou menos. [...] Nós já estamos em 2019 e o meu telefone funciona perfeitamente, não tem problema algum, sabe?" (Entrevistado 1).

"A questão da obsolescência programada, é muito foda porque você pega o celular, igual o meu 7, eu fiquei pouco tempo com ele, mas eu tenho certeza que se eu tivesse ficado mais uns 6 meses, já estaria pifando, tipo assim, ficando lento, aí eu teria que resetar ele todo para ele ficar melhorzinho e depois eu ia ter que vender para comprar um outro" (Entrevistada 13).

"E mesmo ele se tornando obsoleto, que a própria Apple, a Apple faz com que ele se torne obsoleto, ele mesmo assim continua sendo um telefone que se você pegar um iPhone 6, ele pode ser melhor com S10 [modelo de Android], por exemplo. Então, tipo assim, é muita qualidade para um telefone, entendeu?" (Entrevistado 10).
\end{abstract}

O entrevistado de número 1 traz a comparação do iPhone e outros smartphones com relação ao travamento do aparelho, ficando mais lento. Ele afirma que em pouco tempo o aparelho Android começa a travar e perde a velocidade. Já o iPhone, diz durar por muitos anos sem ter esse problema. Já os outros apontam a obsolescência. A entrevistada 13 sente a necessidade de sempre trocar o iPhone por uma versão mais nova e o respondente 10 faz uma comparação com o smartphone Galaxy S10 da Samsung, lançado em 2019, e afirma que mesmo se tornando obsoleto, o iPhone 6, que não é recente, continua sendo melhor, mostrando sua forte preferência pela Apple.

Outras desvantagens são apontadas pelos entrevistados, como o fato do carregador ser diferente dos de aparelho Android, dificultando quando necessita de um empréstimo, a questão do iPhone ser mais frágil com relação a quedas e a manutenção ser mais cara.

"Um caso que se deixa a desejar porque, normalmente todo lugar que você vai, a maioria das pessoas tem Android. 0 carregador de Android de todo mundo é o mesmo. Do iPhone é o único diferente, né?" (Entrevistado 1). 
"O iPhone em si, eu acho ele mais frágil do que os outros porque ele quebra muito fácil, muito fácil. Os outros celulares, nossa, podia cair no chão, podia chutar, podia fazer qualquer coisa que ele não quebrava" (Entrevistado 15).

"Para quem gosta e tem dinheiro para investir, eu recomendaria. Agora não tem tanto dinheiro para investir, aí já fica um pouco mais difícil, porque só uma tela para você trocar do iPhone, no meu no caso, no mínimo uns 150. Isso num mais barato. Num 7 , num 8 da vida, já vai para uns 200 reais para mais" (Entrevistado 5).

Neste trecho da entrevista com o respondente de número 5, pode ser observado que ele afirma que, para se ter um iPhone, deve-se possuir dinheiro para investir. Para quem não tem, seria mais difícil porque existem gastos um pouco altos com a manutenção do aparelho. Ou seja, ele não se considera tão baixa renda, pois existem pessoas que não teriam condições de pagar por essa situação, sendo mais pobres que ele (Barros, 2006; Castilhos, 2007). Com isso, pode ser percebida a tentativa de se diferenciar de indivíduos extremamente pobres, que não podem pagar por esse produto (Barki \& Parente, 2010). Também é possível perceber que a distinção social entre pessoas de baixa renda não ocorre somente pela quantidade de bens que adquirem, mas também por quais produtos eles têm entre suas posses, como é colocado por Senna e Hemai (2017). Existe um pensamento de "saber gastar" (Castilhos, 2007), que seria investir em bens mais valorizados, que dão às pessoas algum tipo de distinção. A base da pirâmide é um segmento que coloca grande ênfase na cultura material (Barros, 2006).

Com relação ao aspecto simbólico, todos afirmam que a marca iPhone é muito forte no mercado e na percepção das pessoas. Conforme apresentado por McCracken (2003), a cultura material tem a habilidade de carregar mensagens de status devido às suas propriedades simbólicas. E, nesta pesquisa, foi possível perceber que ter um iPhone é sinal de status, pois é visto como telefone de pessoas de maior poder aquisitivo. A força da marca é alta em comparação com smartphones de outras marcas, sendo considerado "o famoso", com a estética mais bonita e que chama mais a atenção. Com isso, alguns entrevistados citam a clássica foto no espelho com a maçã da Apple aparecendo.

"Tirar foto no espelho com um iPhone é muito diferente de tirar foto no espelho com celular [se referindo aos outros]. Todo mundo sabe disso. Tanto que quem tem iPhone, às vezes tira [a capinha protetora]" (Entrevistada 6).

"Igual o exemplo de tirar uma foto, você posta lá no Instagram no espelho. [...] Você posta sem capinha, claro, com o iPhone assim dá um outro ar. Não tem nem comparação. Dá um ar de sofisticação, sabe?" (Entrevistada 18).

Alguns afirmam que a Apple é realmente a melhor opção em questão de funcionalidade e desempenho, enquanto outros já apontam que a valorização que o aparelho tem, é simplesmente relacionada à questão de marca, afirmando que existem smartphones melhores e mais evoluídos de outras marcas, mas ainda assim o iPhone é o mais reconhecido. Ou seja, mesmo com vantagens funcionais de marcas concorrentes que apresentam inovações mais atraentes, os entrevistados ainda assim optam pelo smartphone da Apple devido à importância da marca e ao simbolismo que ele carrega. Isso vai de acordo com o que Elliott e Wattanasuwan (1998) apresenta, que todo consumo demanda, consciente ou inconscientemente, valores simbólicos. Se o indivíduo tiver a opção de consumir bens que possuem significados simbólicos, ele o preferirá. Afinal, como afirmam Kim e Jang (2017), os atributos simbólicos são mais determinantes nas intenções de compra do que os funcionais.

"Eu acho que um pouco pela percepção das outras pessoas, mas assim o telefone das outras marcas funciona às vezes a câmera talvez até melhor, mas o que fica famoso é o iPhone" (Entrevistada 7).

"Eu acho que o iPhone é mais valorizado por causa da aparência e por causa do histórico da marca, tipo de ter sido o primeiro, ter sido inovador, entendeu? Só que em questão de sistema e avanço eu acho que a Samsung 'tá' mais à frente" (Entrevistada $11)$.

"A gente vê muito as outras marcas com aparelhos tão bons quanto, mas, tipo assim, as pessoas veem uma inferioridade nos outros" (Entrevistada 16). 
Muitos apontam que não são somente os últimos lançamentos do iPhone que chamam a atenção e fazem com que sejam vistos de forma privilegiada. Até mesmo as versões mais antigas são bem vistas, pois a marca é o ponto importante do aparelho, como é colocado pelo entrevistado de número 5.

\footnotetext{
“Eu 'tava' sem capinha, sem nada, eu 'tava' assim com ele [exibindo o iPhone]. [...] Chama a atenção. E tipo, era o iPhone 5, já tinha sido lançado há séculos, mas mesmo assim chama a atenção. Tinha gente que 'tava' com celular que era Android, mas custava o dobro do preço do iPhone 5, mas ainda chama mais atenção por ser iPhone" (Entrevistado 5).
}

Além dos aspectos positivos em relação à funcionalidade, a marca iPhone carrega grande simbolismo e tem grande influência na sociedade. Mesmo comparando um iPhone mais antigo a outro smartphone de outra marca com preço muito mais elevado, o aparelho da Apple tem maior prestígio. Assim, muitas vezes é criado um vínculo com o produto devido ao aparelho ser um forte impulsionador de status (Tangsupwattana \& Liu, 2018). Os resultados vão de acordo com os obtidos por Jacomino, Biggi e Pépece (2018) que também confirmaram que a marca iPhone é altamente reconhecida e possui diferenciação perante às outras, sendo um instrumento de distinção, como é colocado por Bourdieu (2008), funcionando assim como indicador de pertencimento a uma classe que possui um gosto valorizado, podendo ser considerado "um dos nossos" (Goffman, 1951).

\section{CONSIDERAÇÕES FINAIS}

Neste artigo, buscou-se identificar os diferentes atributos ligados ao simbolismo da marca iPhone em comparação às diferentes marcas de smartphones, na visão dos indivíduos da base da pirâmide. 0 iPhone e a Apple são definidos como marcas fortes que ocupam um patamar diferenciado na percepção das pessoas, sendo apontado como um celular de luxo. Por isso, muitos deles pensam que é um smartphone cobiçado por todos. Os aspectos funcionais mais valorizados entre os entrevistados são a facilidade de uso do sistema IOS e por acreditarem que o aparelho não trava, sendo mais rápido que os outros. A qualidade da câmera também foi muito citada, porém, ela não se limita a um quesito funcional, indo mais a fundo por impactar a autoestima do indivíduo.

Os participantes afirmam que outros smartphones são vistos com inferioridade e muitas vezes os usuários de iPhone chamam seus aparelhos de "meu iPhone" e não de "meu celular". Em caso de perda, alguns declaram que se não possuírem condições no momento, utilizariam temporariamente um aparelho Android até conseguir reunir dinheiro suficiente para adquirir outro smartphone da Apple, sendo a preferência de todos. Esse aparelho tem o poder de oferecer prestígio e superioridade tanto em relação aos aparelhos de outras marcas quanto ao indivíduo perante outras pessoas. Os entrevistados apontam que a maioria das pessoas vê grande status no smartphone da Apple e afirmam que, por mais que muitas vezes não assumam, é visível a compra por status. Existe uma ligação entre iPhone e riqueza, sendo o prestígio oferecido pelo aparelho algo que agrada os indivíduos de baixa renda. Segundo eles, pessoas de classes inferiores são as que mais atribuem status ao iPhone e que a utilização desse e de outros produtos de marcas caras são com a intenção de mostrar que têm condições financeiras para adquirir e que também podem ter status.

As justificativas apresentadas pelos respondentes para o uso do aparelho são por questões funcionais como praticidade e rapidez, sendo melhor para o trabalho e estudo. Porém, no decorrer da entrevista questões simbólicas acabaram surgindo e, mesmo com a dificuldade de assumirem a compra por status, isso foi percebido. Não declarar a compra por status pode ser por não querer admitir ou também por estar no inconsciente, não sendo algo tão óbvio na mente do consumidor. Logo, existem evidências de que, embora sejam mais apontados aspectos funcionais, as questões simbólicas prevalecem, como é apontado por Elliott e Wattanasuwan (1998) e Kim e Jang (2017), pois mesmo que outros smartphones de outras marcas sejam melhores, não conseguem derrubar todo o simbolismo do iPhone, sendo este o principal motivo da compra.

Este estudo buscou ampliar o conhecimento na base da pirâmide, unindo consumidores de baixa renda ao consumo de status e apresentando resultados empíricos referentes a aspectos 
simbólicos e de status relacionados à posse do smartphone iPhone. Com isso, os achados da pesquisa podem colaborar tanto com pesquisadores quanto com o mercado, gerando informações relevantes para entender melhor este segmento de consumidores. A falta de estudos neste tema impede que seja percebida a grande importância que é dada por eles à cultura material e ao consumo hedônico, sendo marcas que oferecem prestígio muito valorizadas por essa classe.

Uma grande limitação deste estudo foi encontrar um critério de classificação da baixa renda. Com isso, os autores optaram por utilizar o de duas Universidades Federais. Ao contar com estudantes universitários como sementes da bola de neve, a maioria do corpus foi composta por estes alunos. Isso pode ter causado uma delimitação da análise. Além disso, esta pesquisa se limitou a usuários de iPhone de baixa renda, de modo a compreender as motivações para o uso e o significado do aparelho para eles. Assim, sugere-se para pesquisas futuras entrevistar pessoas que não possuem o smartphone iPhone de modo a descobrir como enxergam o aparelho e seus usuários. Também se propõe um estudo feito com um corte específico, envolvendo usuários de iPhone que tenham renda de até um salário mínimo.

\section{Referências}

Albuquerque, A. M. de. (2009). Avaliação da Técnica de Amostragem "Respondent-Driven Sampling" na estimação de prevalências de doenças transmissíveis em populações organizadas em redes complexas. Dissertação de Mestrado, Saúde Pública, ENSP, Rio de Janeiro.

Barbosa, L. (2004). Sociedade de consumo. Jorge Zahar, Rio de Janeiro.

Bardin, L. (1977). Análise de conteúdo (L. A. Neto, \& A. Pinheiro, Trad). Edições 70, Lisboa.

Barki, E., \& Parente, J. (2010). Consumer behavior of the base of the pyramid marketing in Brazil. Greener Management International, 56, 11-23.

Barros, C. (2006). Consumo, Hierarquia e Mediação: Um Estudo Antropológico no Universo das Empregadas Domésticas. XXX Encontro da ANPAD, Salvador.

Barros, C., \& Rocha, E. (2007). Lógica de Consumo em um Grupo das Camadas Populares: Uma Visão Antropológica de Significados Culturais. XXXI Encontro da ANPAD, Rio de Janeiro.

Baumhammer, P., Silva, M. G., \& da Costa, M. F. (2017). Aspectos simbólicos do smartphone e o eu estendido: um estudo do comportamento do consumidor português. Revista Interdisciplinar de Marketing, 7(2), 175-190.

Bezerra, C. O., \& Davel, E. P. B. (2017). Tradição e inovação na era digital: valor simbólico, cultura e marketing. REAd-Revista Eletrônica de Administração, 23(3), 288-312.

BBC. (2018). A Apple é a primeira empresa pública no valor de US $\$ 1$ trilhão. https://www.bbc.com/news/business-45050213

Bhat, S., \& Reddy, S. K. (1998). Symbolic and functional positioning of brands. Journal of consumer marketing, 15(1), 32-43.

Bourdieu, P. (2008). A distinção: crítica social do julgamento (D. Kern, \& G. J. F. Teixeira, Trad). Zouk, Porto Alegre.

Castilhos, L. B. (2007). Subindo o Morro: Consumo, Posição Social e Distinção Entre Famílias de Classes Populares. XXXI Encontro da ANPAD, Rio de Janeiro.

Chaves, S. R. N., \& Rodríguez-González, L. (2013). Consumo simbólico: una perspectiva sociocultural en la comprensión del comportamiento del consumidor. Revista Iberoamericana de Psicología, 6(2), 27-34.

EAESP-FGV. 29 (2018). 29a Pesquisa Anual do Uso de TI. https://eaesp.fgv.br/sites/eaesp.fgv.br/files/pesti2018gvciappt.pdf

Elliott, R., \& Wattanasuwan, K. (1998). Brands as symbolic resources for the construction of identity. International journal of Advertising, 17(2), 131-144.

Esmaeilpour, F. (2015). The role of functional and symbolic brand associations on brand loyalty: a study on luxury brands. Journal of Fashion Marketing and Management, 19(4), 467-484. 
Folha De São Paulo. (2018). Ter iPhone é sinal de riqueza nos Estados Unidos, aponta pesquisa. https://www1.folha.uol.com.br/mercado/2018/07/ter-iphone-e-sinal-de-riqueza-nos-estadosunidos-aponta-pesquisa.shtml

Goffman, E. (1951). Symbols of class status. The British Journal of Sociology, 2(4), 294-304.

Heracleous, L. (2013). Quantum strategy at apple inc. Organizational Dynamics, 42(2), 92-99.

Jacomino, G. P., Biggi, L. M., \& Pépece, O. M. C. (2018). M(eu)Phone: os significados de consumo para o consumidor de iPhone que não possui renda própria. Revista Interdisciplinar de Marketing, 8(2), 99-115.

Kim, D., \& Jang, S. (2017). Symbolic consumption in upscale cafés: Examining Korean gen Y consumers' materialism, conformity, conspicuous tendencies, and functional qualities. Journal of Hospitality \& Tourism Research, 41(2), 154-179.

Kolk, A., Rivera-Santos, M., \& Rufín, C. (2014). Reviewing a decade of research on the "base/bottom of the pyramid" (BOP) concept. Business \& Society, 53(3), 338-377.

Laugesen, J., \& Yuan, Y. (2010). What factors contributed to the success of Apple's iPhone? 2010 Ninth International Conference on Mobile Business and 2010 Ninth Global Mobility Roundtable (ICMBGMR).

Martins, V. M. C., Oliveira, M. O. R. de, \& Corso, K. B. (2018). Sou o que eu Consumo? Smartphones e o Self Estendido a Luz de Paradoxos Tecnológicos. Revista Brasileira de Marketing, 17(3), 329-343.

Mccracken, G. (2003). Cultura \& consumo. Mauad Editora Ltda, Rio de Janeiro.

Natt, E. D. M. et al. (2017). Baixa renda: o consumo simbólico e o comércio informal de acessórios femininos. Revista de Administração em Diálogo - RAD, 19(1), 138-163.

Özbölük, T., \& Dursun, Y. (2017). Online brand communities as heterogeneous gatherings: a netnographic exploration of Apple users. Journal of Product \& Brand Management, 26(4), 375385.

Prahalad, C. K. (2005). The fortune at the bottom of the pyramid: eradicating poverty through profits. Pearson Education, New Jersey.

Senna, S. S., \& Hemai, M. W. (2017). Significados associados a shopping centers por consumidores da classe C. Revista de Administração da UNIMEP, 15(4), 93-116.

Tangsupwattana, W., \& Liu, X. (2018). Effect of emotional experience on symbolic consumption in Generation Y consumers. Marketing Intelligence \& Planning, 36(5), 514-527.

Veiga, L., \& Gondim, S. M. G. (2001). A utilização de métodos qualitativos na ciência política e no marketing político. Opinião Pública, 7(1), 1-15.

Vinuto, J. (2014). Amostragem em bola de neve na pesquisa qualitativa: um debate em aberto. Temáticas, 22(44), 203-220.

Yurdakul, D., Atik, D., \& Dholakia, N. (2017). Redefining the bottom of the pyramid from a marketing perspective. Marketing Theory, 17(3), 289-303. 